\title{
DGCR8 Gene Mutation
}

National Cancer Institute

\section{Source}

National Cancer Institute. DGCR8 Gene Mutation. NCI Thesaurus. Code C158670.

A change in the nucleotide sequence of the DGCR8 gene. 